\title{
Arthritis, CTCAE
}

National Cancer Institute

\section{Source}

National Cancer Institute. Arthritis, CT CAE. NCI Thesaurus. Code C143299.

A disorder characterized by inflammation involving a joint. 